\title{
Increasing efficiency of iron ore magnetic separation by using ultrasonic technologies
}

\author{
Vladimir Morkun ${ }^{1, *}$, Natalia Morkun ${ }^{1}$, Vitalii Tron ${ }^{1}$, Vladimir Golik ${ }^{2}$, and Arkadii Davidkovich ${ }^{3}$ \\ ${ }^{1}$ Kryvyi Rih National University, Automation, Computer Science and Technology Department, 11 Vitalii Matusevich Str., Kryvyi Rih, \\ 50027, Ukraine \\ ${ }^{2}$ North-Caucasian State Technological University, Mining Department, 44 Cosmonaut Nikolayev Str. Vladikavkaz, Russia \\ ${ }^{3}$ Research Department, MCRSS, Boston, USA
}

\begin{abstract}
The research is aimed at solving the topical problem of enhancing efficiency of iron ore magnetic separation by applying ultrasonic technologies to identify optimal technological parameters of magnetic separation, improving controlled structural parameters of a magnetic separator and pretreating slurry by highenergy ultrasound to clean the ore material surface from fine-dispersed particles of minerals and slime, as well as disintegrate ore aggregates fed to the magnetic separator. The main tasks involve identifying regularities of influence of slurry pretreatment by high-energy ultrasound on properties of iron ore magnetic separation, determining regulations of improving technological and controlled structural parameters of the magnetic separator using ultrasonic methods, developing and substantiating methods to enhance efficiency of iron ore magnetic separation by applying ultrasonic technologies.
\end{abstract}

\section{Introduction}

Sustainable industrial development calls for solving the topical problem of reducing costs and energy-intensity of iron ore mining and processing [1-5]. Energy intensity of Ukraine's mining and metallurgical complex greatly exceeds that of advanced industrial countries $[2,3\}$. Power consumption of iron ore concentration processes and equipment substantially depends on properties of ore subjected to processing [6-8]. Nowadays, about 5-8 mineral and technological types of ore are processed simultaneously at Kryvyi Rih mining and concentration plants $[2,7]$. It is worth noting that each mineral and technological type of iron ore demands such grinding rate to maintain certain granulometric composition in compliance with the size of useful component inclusions, thus ensuring the best ore-grain release and enhancing efficiency of subsequent sorting and separation $[9,10]$.

Application of ultrasonic technologies to nondestructive control is one of promising methods to enhance efficiency of iron ore concentration, this involving attainment of operative data on technological processes and treatment of ore particles by controlled high-energy ultrasound, in particular, by forming cavitation processes in iron ore slurry [11-13].

The research is aimed at solving the topical problem of enhancing efficiency of iron ore magnetic separation by applying ultrasonic technologies to identifying optimal technological parameters of magnetic separation, improving controlled structural parameters of a magnetic separator and pretreating slurry by high-energy ultrasound to clean the ore material surface from fine-dispersed particles of minerals and slime, as well as disintegrating ore aggregates fed to the magnetic separator. The main tasks involve identifying regularities of influence of slurry pretreatment by high-energy ultrasound on properties of iron ore magnetic separation, determining regulations of improving technological and controlled structural parameters of the magnetic separator using ultrasonic methods, developing and substantiating methods to enhance efficiency of iron ore magnetic separation by applying ultrasonic technologies.

[14-15] suggest applying the ultrasonic method to controlling suspension velocity and accumulating magnetic material inside the wet magnetic separator of low-intensity. To do this, [14] uses the acoustic system of back-scattering and the ultrasonic method to profile flow velocity. Simultaneously, intensity of the back-scattering signal is used to obtain data on local concentration of solids in the flow and accumulation of magnetic materials.

[16] deals with dynamics of slurry magnetic particles in the magnetic separator of low-intensity. The research suggests modelling dynamics of magnetic particles by tracing individual trajectories by means of the COMSOL Multiphysics software package. The research results reveal various distribution of the block of constant magnets and percentage of coupled particles affecting efficiency of separation. [17] considers the simulation model of the dry rotary drum magnetic separator with distribution of probable trajectories of particles leaving the magnetic separator drum. Empiric relationships are used to combine particles' trajectories after their discharge from the drum by its rotation and magnetic field.

\footnotetext{
* Corresponding author: morkunv@gmail.com
} 
[18] is aimed at investigating into the influence of ore particles accumulated in the magnetic separator on separation processes. There are presented research results on profiles of accumulation of particles and their parameters. It is ascertained that pulsating suspension affects the areas of paramagnetic seizure of particles. At the same time, increased magnetic induction within a certain range can also increase particle accumulation to a great extent. [19] deals with researches into ore material separation in various types of magnetic separators. It indicates that a complex system of interrelated factors and structural parameters of magnetic separators greatly impacts efficiency of the latter. The research is aimed at studying the influence of external factors on efficiency criteria of magnetic separation. Meanwhile, the researches of the mentioned scholars neglect technologies of pretreating solid particles of ore slurry, in particular the ultrasound-based ones.

[20] suggests a magnetic separator model that considers mineralogical data of ore flows when treating three ore types depending on their content of the useful component. There are suggested efficiency indices of magnetic separation ranked by their significance that also take into account the mentioned ore classification. The research testifies to the impact of ore mineralogical characteristics on indices of magnetic separation.

$[21,22]$ investigate into ore material properties affecting separation in the magnetic separator. However, the above researches consider only a limited range of properties, this not allowing reliable recognition of mineralogical and technological types of ore materials.

$[23,24]$ describe the experiment results of separating ore materials of various mineralogical properties during magnetic separation. There are determined optimal mode parameters of separation depending on certain mineralogical characteristics to increase $\mathrm{Fe}$ content in concentrates. However, the mentioned researches do not focus on nondestructive control of solid slurry properties aimed at improving efficiency of magnetic separation.

Thus, analysis of foreign and national researches on the issues under study reveals a great number of scientific works dealing with methods of enhancing efficiency of technological parameters of ore concentration, improving controlled structural parameters of technological aggregates. On the other hand, it is worth indicating that little attention is paid to the issues of slurry pretreatment by high-energy ultrasound to clean the ore material surface from fine-dispersed mineral particles and slime and disintegration of ore aggregates fed to the magnetic separator. Considering this, integrated application of mentioned methods and means requires development of a relevant mathematical apparatus and engineering designs. It is necessary to conduct researches, improve available mathematical models of technological processes and elaborate a set of ultrasonic methods of operative control over iron ore properties and its pretreatment.

\section{Materials and methods}

The research aims to improve efficiency of iron ore magnetic separation by integrated application of ultrasonic technologies to enhancing technological and structural parameters of the magnetic separator as well as cleaning the ore material surface and disintegrating ore aggregates.

The research idea implies improved efficiency of iron ore magnetic separation due to identifying technological parameters of the process under study (efficiency, solids concentration, granulometric composition, useful component release), optimal controlled structural parameters of the magnetic separator (the angle of the magnetic unit, the rotation speed, distances between the overflow and the separation drum) and slurry pretreatment by high-energy ultrasound to clean the ore material surface from fine-dispersed particles of minerals and slime and disintegration of ore aggregates fed to the magnetic separator.

The working hypothesis involves integrated application of ultrasonic technologies to investigating into regularities of iron ore magnetic separation that will enable substantiating complex methods of improving efficiency of iron ore magnetic separation, enhancing controlled structural parameters of the magnetic separator and pretreatment of slurry by high-energy ultrasound to clean the ore material surface from fine-dispersed particles of minerals and slime and disintegration of ore aggregates fed to the magnetic separator.

Specific features of the research structure and components imply the fact that achievement of the project aim provides for complex investigations comprising identification of regularities of impacts of pretreating slurry by high-energy ultrasound on characteristics of iron ore magnetic separation; determination of regularities of improving technological and controlled structural parameters of the magnetic separator using ultrasonic methods; development and substantiation of methods to enhance efficiency of iron ore magnetic separation by applying ultrasonic technologies.

Thus, it is required to combine research results in the following directions: theoretical and practical research into iron ore magnetic separation; methods and means of operative control over physical-mechanical and chemicalmineralogical properties of iron ore slurry, as well as methods of improving indices of iron ore magnetic separation.

The mathematical model of dynamic effects of highenergy ultrasound impacting solids in the slurry flow is the key element of the research methods. The given model enables formation of conditions for pretreatment of the ore material surface and disintegration of ore aggregates fed to the magnetic separator. Simultaneously, the model considers dependency of the state of fine-dispersed slime, particles of ore grains of ferromagnetic slurry and flocculated unreleased ore aggregates on parameters of ultrasonic oscillations. The integrated system of methods of measuring ultrasonic dynamics of all technological variables enables improved substantiation of the concept of influence of technological factors on qualitative characteristics of magnetic separation of magnetite quartzite of Kryvyi Rih iron ore basin. The method of identifying processes of separation, delivery and dehydration of materials directly inside the magnetic separator under various operating modes will be 
developed on the basis of ultrasonic measurements of changes in concentration, velocity and sizes of ore slurry solids.

The method is noted for application of the first and the second harmonics of volume and surface ultrasonic oscillations propagating in the slurry and along contacting surfaces as measuring parameters of intensity. Also, the research methods include the method of increasing efficiency of iron ore magnetic separation that encapsulates slurry pretreatment by high-energy ultrasound to clean the ore material surface, from finedispersed particles of minerals and slime and disintegration of ore aggregates fed to the magnetic separator, determination of optimal technological parameters of magnetic separation (efficiency, concentration of solids, granulometric composition, the release rate of the useful component) and optimal controlled structural parameters of the magnetic separator by using ultrasonic measurements.

\section{Results and discussion}

To simulate the ultrasonic pressure source which is timevariant, the k-wave software package for MATLAB is used in the two-dimensional heterogeneous medium of propagation $[25,26]$. The initial distribution of pressure is determined by adjusting parameters of the source.p0. To identify the pressure time-variant source, there can be established both a source mask (that identifies the model net points belonging to the source), and the input of the time-variant source. The source mask is determined by assigning of the binary matrix of the same sizes as the calculated net where 1 is presented by the net points forming part of the source [27].

When acoustic waves reach the edge of the calculated area, they are absorbed by a specific type of the anisotropic absorbing boundary layer [28, 29]. Effects produced by this layer can be observed when propagating waves approach the edge of the calculated area. By default, this layer occupies a band of 20 net points around the domain edge inside the calculated domain identified by kWaveGrid. To avoid side effects, one should not place the source or the sensor points inside this layer. As an alternative, to obtain a perfectly coordinated layer, it can be established outside the calculated domain set by the user.

The absorbing boundary layer possesses four properties each of which can be controlled by additional input parameters [28, 30].

Sizes of the absorbing layer on each domain edge are conditioned by the parameter PMLSize in units of the points. By default, there 20 net points in one- and twodimensional spaces and 10 net points in the threedimensional space. If the size is a single value, it is used for all Cartesian coordinates. Optionally, the size for each direction can be established separately by setting the Size value [x_size, $y \_$size] in the two-dimensional space and [x_size, $\bar{y} \_$size, $\bar{z} \_$size] in the three-dimensional one.

Absorption inside the absorbing layer is set by the parameter Alpha in the Napier units on the net points. By default, the parameter equals 2 for all the sizes. If absorption is indicated as a single value, it is used for all Cartesian directions. Besides, absorption for each direction can be established separately by setting the Alpha value [x_alpha, y_alpha] in the two-dimensional space and [x_alpha, y_alpha, z_alpha] in the threedimensional one.

The absorbing layer can be located so that it is inside or outside the calculated net created by the user while changing the value of the logic flag Inside. If Inside is established as false, the net inputs increase on each edge by the size set by Size.

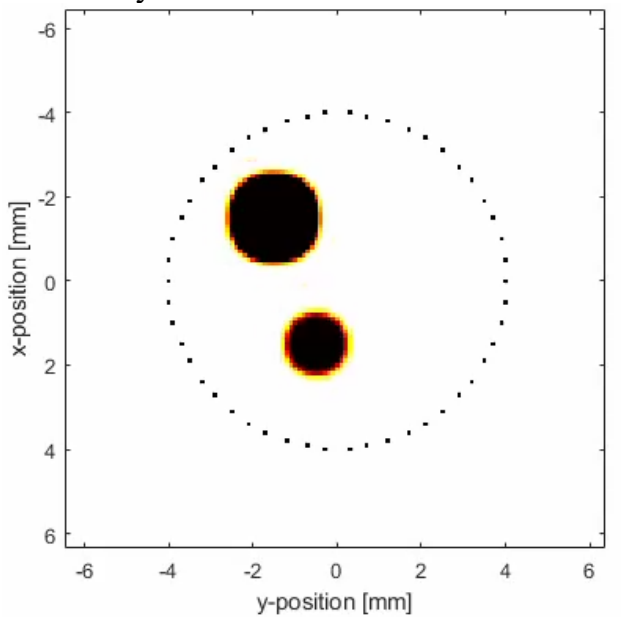

a)



b)

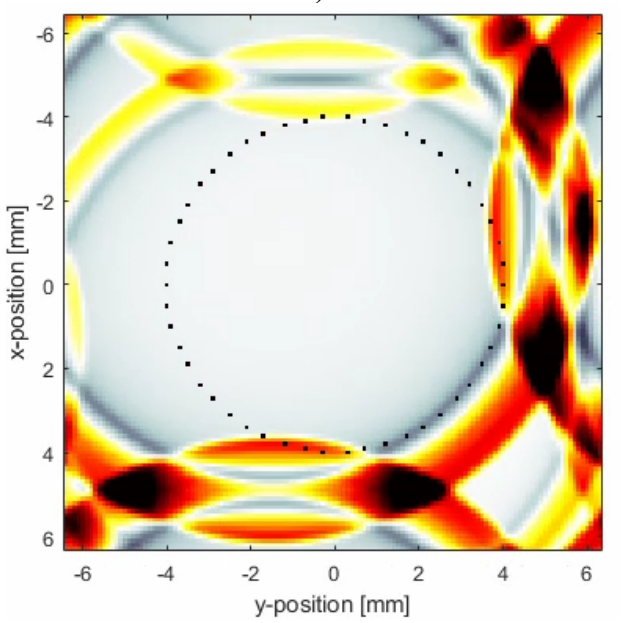

c)

Fig. 1. Dynamics of the acoustic pressure field propagating with the absorbing boundary layer switched off. 
Visibility of the absorbing layer within the simulated space that is reflected during simulation is controlled by the logic input parameter Plot (by default set as true).

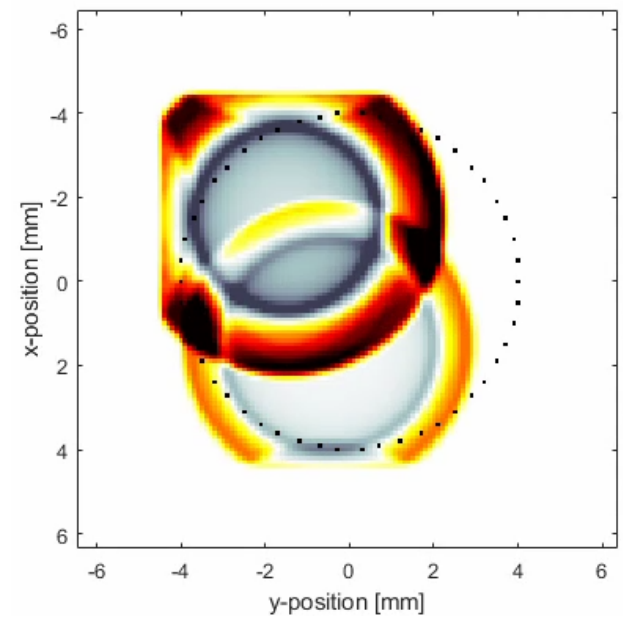

a)

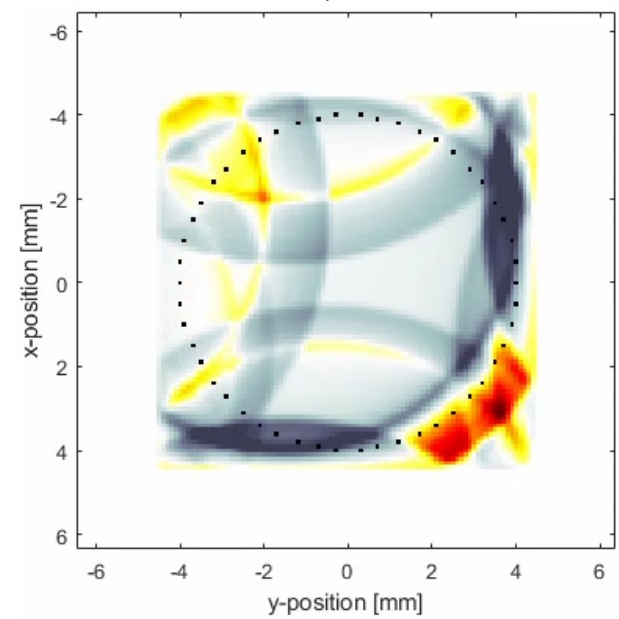

b)

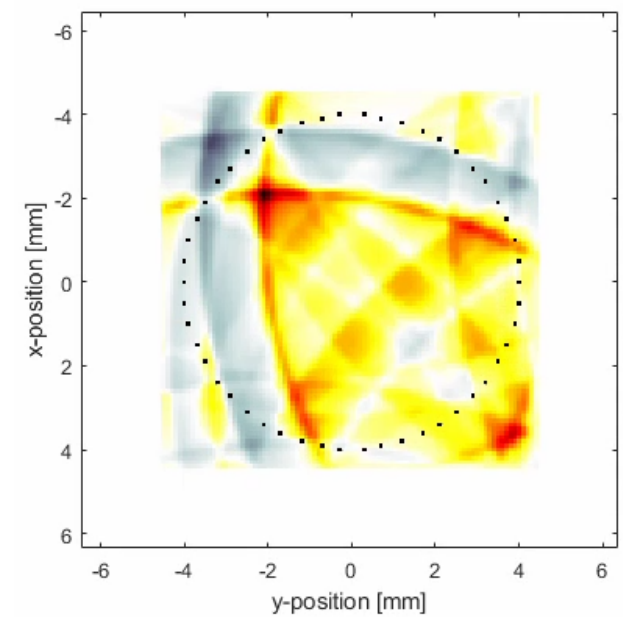

c)

Fig. 2. Dynamics of the acoustic pressure field propagating with the propagation parameter value being too high

To make simulation more accurate, one should make sure the initial pressure distribution and the sensor mask are not within the boundary layer. This can be avoided by setting Inside to be false. Yet, calculation time will anyway depend on the general size of the net including the boundary layer (i.e. calculations will be the fastest for the nets where the total number of net points in each dimension is given twice).

Let us consider some specific cases of adjusting the absorbing boundary layer - without absorption, with too high absorption, the partially effective boundary layer, and the boundary layer set outside the calculated domain.

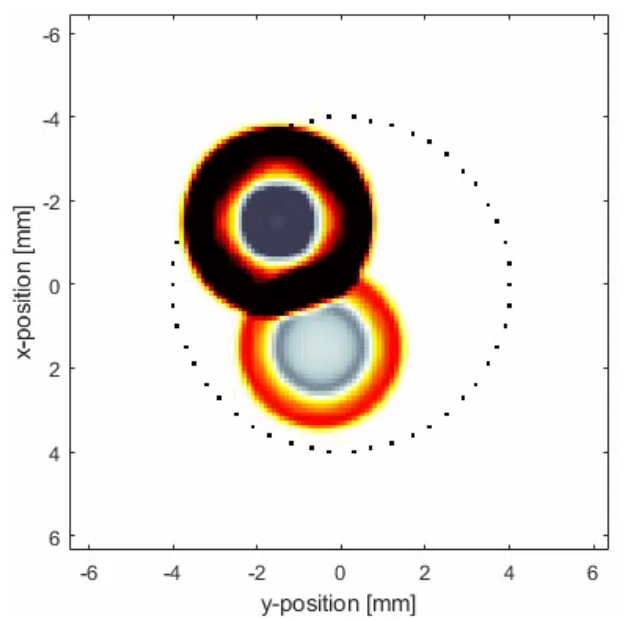

a)

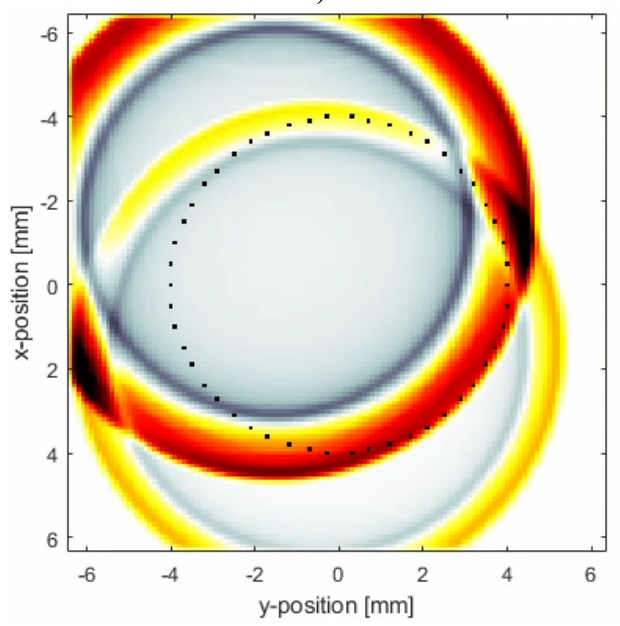

b)

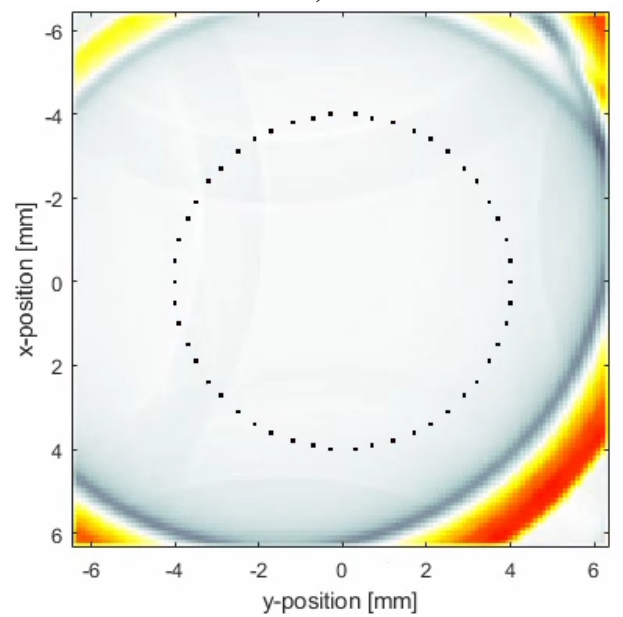

c)

Fig. 3. Dynamics of the acoustic pressure field propagating with partially effective boundary layer

In software, certain parameters of the absorbing boundary layer are selected by the conventional operator where the variable of choosing the model characteristics 
is set manually and can take the value from the preestablished totality.

The effect of the absorbing boundary layer can be visualized by switching it off completely. To do this, the parameter Alpha is initiated by 0 . In such a way, the zero absorption is established inside the layer and the waves leaving one side of the domain reappear on the opposite side. Fig. 1 visualizes dynamics of the acoustic pressure field propagating.

A similar effect is observed if the Alpha value is set too high. It makes the waves reflect from the boundary layer (Fig. 2).

Efficiency of the absorbing boundary layer depends on its size and absorption as well the time step used for modelling: the more time intervals a wave spends in the boundary layer, the more it is absorbed.

An effective absorbing boundary layer can be partially simulated by reducing its size, i.e. setting 2 for the additional input Size.

The boundary layer absorbs part of the waves approaching boundaries of the simulation area. Part of reflected waves watched in the previous example can still be perceived by sensors (Fig. 3).

By default, the absorbing boundary layer will be in the net determined by the user, so the source and the sensor should not be determined in this area.

\section{Conclusions}

Thus, the working hypothesis of the project implies the integrated application of ultrasonic technologies to investigating into regularities of iron ore magnetic separation that enables substantiation of integrated methods of improving efficiency of iron ore magnetic separation by enhancing technological parameters of magnetic separation, improving controlled structural parameters of the magnetic separator and slurry pretreatment by high-energy ultrasound to clean the ore material surface from fine-dispersed particles of minerals and slime and disintegration of ore agglomerates fed to the magnetic separator.

\section{References}

1. V.I. Lyashenko, Environment-saving technologies for mining complex deposits. Mine-Surv. J., 1, 10-15 (2015)

2. M.I.Stupnik, V.O. Kalinichenko, O.V. Kalinichenko, I.O. Muzika, M.B. Fed'ko, S.V. Pismennyi. The research of strain-stress state of magnetite quartzite deposit massif in the condition of mine "GigantGliboka" of central iron ore enrichment works (CGOK). Metallurgical and mining industry, 7, 377383 (2015)

3. A. Kupin, D. Kuznetsov, I. Muzyka, D. Paraniuk, O. Serdiuk, O. Suvorov, V. Dvornikov, The concept of a modular cyberphysical system for the early diagnosis of energy equipment. East.-European J. of Enterprise Technol., 4 (2-94), 71-79 (2018). doi:10.15587/1729-4061.2018.139644
4. V.I. Komashenko, I.V. Erohin, Concept of reducing hazardous contamination of the mining regions of KMA. Mining inform. and analisys bull., 2, 10-16 (2014)

5. , M. Stupnik, V. Kalinichenko, S. Pysmennyi, O. Kalinichenko, M. Fedko. Method of simulating rock mass stability in laboratory conditions using equivalent materials. Mining of Mineral Deposits, 10(3), 46-51, (2016) doi: 10.15407/mining10.03.046

6. A. Bublikov, V. Tkachov, Automation of the control process of the mining machines based on fuzzy logic. Naukovyi Visnyk Natsionalnoho Hirnychoho Universytetu, 3, 112-118 (2019)

7. M. Stupnik, O. Kalinichenko, V. Kalinichenko, S. Pysmennyi, O. Morhun, Choice and substantiation of stable crown shapes in deep-level iron ore mining. Mining of Mineral Deposits, 12(4), 56-62 (2018) doi: 10.15407/mining12.04.056

8. M. Stupnik, V. Kolosov, S. Pysmennyi, K. Kovbyk. Selective mining of complex stuctured ore deposits by open stope systems. E3S Web of Conferences, 123, 01007 (2019) doi: 10.1051/e3sconf/201912301007

9. M.B. Fedko, I.O. Muzyka, S.V. Pysmennyi, O.V. Kalinichenko, Determination of drilling and blasting parameters considering the stress-strain state of rock ores. Naukovyi Visnyk Natsionalnoho Hirnychoho Universytetu, 1, 37-41 (2019) doi: 10.29202/nvngu/2019-1/20

10. I. Kotov, O. Suvorov, O. Serdiuk, Development of methods for structural and logical model unification of metaknowledge for ontologies evolution managing of intelligent systems. East.-European J. of Enterprise Technol., 2(4-98), 38-47 (2019). doi:10.15587/17294061.2019.155410

11. V. Golik, V. Morkun, N. Morkun, V. Tron Investigation of Mechanochemical Leaching of NonFerrous Metals. Acta Mechanica et Automatica, 13(2), 113-123. (2019) doi: 10.2478/ama-2019-0016

12. V.S. Morkun, N.V. Morkun, V.V. Tron, T.S. Sulyma, Synthesizing models of nonlinear dynamic objects in concentration on the basis of Volterra-Laguerre structures. Naukovyi Visnyk Natsionalnoho Hirnychoho Universytetu, 2020(2), 30-36 (2020) doi: 10.33271/nvngu/2020-2/030

13. V. Morkun, N. Morkun, V. Tron, S. Hryshchenko, , O. Serdiuk, T. Sulyma, System of multi-channel ultrasonic and radiometric measurements for determining characteristics of concentration products. 2019 IEEE 39th International Conference on Electronics and Nanotechnology, ELNANO 2019 - Proceedings, 664-667, 8783226 (2019)

14. J. F. Stener, J. E. Carlson, B. I. Palsson, A. Sand, Direct measurement of internal material flow in a bench scale wet low-intensity magnetic separator. Minerals Engineering. 91. 55-65. (2016) doi: 10.1016/j.mineng.2015.10.021

15. A. Jordens, Y.P. Cheng, K.E. Waters, A review of the beneficiation of rare earth element bearing minerals. 
Miner. Eng., 41, 97-114 (2013). doi: 10.1016/j.mineng.2012.10.017

16. F. Wang, H. Zhao, H. Dai, W. Du, Fully coupled multi-physics modeling of the multi-type magnetic particles dynamic behavior in low intensity magnetic separator. Physicochemical Problems of Mineral Processing, 55(1), 163-172 (2019) doi: $10.5277 /$ ppmp 18117

17. C. Bertrand, C. Bazin, P. Nadeau, Simulation of a Dry Magnetic Separation Plant. Advances in Metallurgical and Material Engineering, 1(1),15-28. (2018) doi: 10.36959/508/394

18. Z. Hu, J. Zhang, J. Liu, Y. Tang, X. Zheng, Model of particle accumulation on matrices in transverse field pulsating high gradient magnetic separator. Minerals Engineering, 146, 106105 (2020) doi: 10.1016/j.mineng.2019.106105.

19. M. Dworzanowski, Optimizing the performance of wet drum magnetic separators. Journal of the Southern African Institute of Mining and Metallurgy. 110(11), 643-653 (2010)

20. E. Charikinya, J. Robertson, A. Platts, M. Beckera, P. Lamberg, D. Bradshaw, Integration of mineralogical attributes in evaluating sustainability indicators of a magnetic separator. Minerals Engineering, 107, 5362 (2017)

21. S. K. Tripathy, V. Singh, Y. R. Murthy, P. K. Banerjee, N. Suresh, Influence of process parameters of dry high intensity magnetic separators on separation of hematite. International Journal of Mineral Processing, 160, P. 16-31 (2017)

22. V.S. Biletskii, K.L. Shpyliovii, Vyluchennya vazhkykh mineraliv $\mathrm{z}$ ridkisnometalichnoyi rudy $\mathrm{u}$ vidtsentrovomu poli (Extraction of heavy minerals from rare metal ore in a centrifugal field). Visnyk Kryvorizkoho natsional'noho universytetu, 40. 68-73 (2015)

23. S. A. Hashemi, B. Rezai, M. R. Tavakoli Mohammadi, S. Javanshir, Characterization and concentration studies of Jalal Abad iron mine. Archives of Mining Sciences, 58, 3, 729-745 (2013)

24. O. M. Ponomarenko, O. B. Bryk, N. O. Dudchenko, V. D. Yevtyekhov, Prystriy dlya separatsiyi vysokodyspersnoyi zalizorudnoyi syrovyny za dopomohoyu kombinovanoho vplyvu postiynykh ta zminnykh mahnitnykh poliv (Device for separation of highly dispersed iron ore by means of the combined influence of constant and alternating magnetic fields). Nauka ta innovatsiyi : nauk.-pr. zhurn. NAN Ukrainy, 6, 5-9 (2017)

25. J. Jaros, A. P. Rendell, B. E. Treeby, Full-wave nonlinear ultrasound simulation on distributed clusters with applications in high-intensity focused ultrasound, arXiv:1408.4675 (2014)

26. B. E. Treeby, Modeling nonlinear wave propagation on nonuniform grids using a mapped k-space pseudospectral method. IEEE Trans. Ultrason. Ferroelectr. Freq. Control, 60, 10, 2208-2213 (2013) doi: 10.1109/TUFFC.2013.2812
27. B. E. Treeby, J. Jaros, A. P. Rendell, B. T. Cox Modeling nonlinear ultrasound propagation in heterogeneous media with power law absorption using a k-space pseudospectral method. J. Acoust. Soc. Am., 131, 6, 4324-4336 (2012) doi: 10.1121/1.4712021

28. B. E. Treeby, J. Jaros, A. P. Rendell, and B. T. Cox, Modeling nonlinear ultrasound propagation in heterogeneous media with power law absorption using a k-space pseudospectral method. J. Acoust. Soc. Am., 131, 6, 4324-4336 (2012) doi: $10.1121 / 1.4712021$

29. B. E. Treeby, B. T. Cox, A k-space Green's function solution for acoustic initial value problems in homogeneous media with power law absorption, J. Acoust. Soc. Am., 129, 6, 3652-3660 (2011) doi: $10.1121 / 1.3583537$

30. B. E. Treeby, B. T. Cox, Modeling power law absorption and dispersion for acoustic propagation using the fractional Laplacian J. Acoust. Soc. Am., 127, 5, 2741-2748 (2010) doi: 10.1121/1.3377056 